\title{
Do golem ao analisante: o analista não é um baal shem*
}

From the golem to the analysand: the analyst is not a baal shem

Francisco José Bezerra Santos **

Resumo: O inominável, o inefável, fazendo marca pela letra e inscrevendo-se na carne. Na mitologia, é possível encontrar uma ilustração desse efeito por meio da lenda do golem, tema recorrente na literatura.

Palavras-chave: Psicanálise. Judaísmo. Golem.

Abstract: The unnameable, inexpressible, making brand by letter and by registering in the flesh. In mythology, it is possible to find an illustration of that fact by means of the legend of the golem, recurring theme in literature.

Keywords: Psychoanalysis. Judaism. Golem.

Falo da marca sobre a pele, onde se inspira, nessa fantasia, o que nada mais é que um sujeito que se identifica como sendo objeto de gozo".

Lacan

Há alguns meses eu o escutava regularmente. Em algumas sessões, apenas silêncio. Noutras, ele relatava histórias que testemunhavam sua errância enquanto sujeito. Trajetórias intermináveis e sempre reiniciadas: a análise ainda continuava a ser apenas mais um ponto de passagem em seus inúmeros roteiros. Um dia, a angústia manifestou-se ante a um apelo ao qual ele não possuía a condição para responder e repetia entre lágrimas: “Eu não posso fazer nada, eu não sou o senhor da palavra".

A angústia e a frase proferida. Lacan dizia que a angústia era um afeto do sujeito, sinal de que o desejo do Outro o atingia e, como algo da ordem do real, ela não enganava. ${ }^{1}$ Eis aí, ironicamente, a "sabedoria" do psicótico: sabe que não é senhor da palavra, sabe que em seu próprio corpo o Outro produz efeito e ele, em verdade, é falado antes do que fala. Na crise, a mensagem do Outro o atinge diretamente, sem o ilusório hábito do eu a amenizar o quanto há de mortífero neste desejo.

De Schreber a Artaud, produziram-se escritos que foram tentativas, para tais sujeitos, de subjetivar a experiência da psicose. Contudo, não é necessário recorrer apenas a ela para apontar o efeito do real, pois este se manifesta, também, na neurose e sua presença marca a condução de uma análise que coloque em cena a estrutura do fantasma fundamental. Na passagem, o sujeito saberá que ele não é mesmo o senhor da palavra.

$\mathrm{Na}$ transmissão da psicanálise, Lacan procurou, a partir de certo momento, evitar os efeitos imaginários de seu nome sobre seu ensino e buscou decantar algo de irredutível que suportasse as mais diversas interpretações. E, conseqüentemente à elaboração dos três registros - R. S. I - acreditou haver encontrado um modo de transmitir algo da ordem real, dizendo que: "o real só poderia inscrever-se por um impasse de formalização. Aí é que eu acreditei poder desenhar seu modelo a partir da formalização matemática, no que ela é a elaboração mais avançada que nos tem sido dada produzir da significância". Nessa via, Lacan afirmou também que "só a matematização atinge um 
real”2 possibilitando a Melman acrescentar que as próprias fórmulas eram o real, a dedução lógica, embora ousada, da idéia do inconsciente estruturado como uma linguagem: ele não seria constituído por uma seqüência de significantes ou fonemas, mas por uma seqüência de letras. ${ }^{3}$

Se a escrita "é um traço onde se lê um efeito de linguagem", ${ }^{4}$ há que pensar na articulação dos três registros em relação ao produto da escritura. A letra é esse traço, marca na superfície, inscrição que aponta para algo não simbolizável. O exemplo da aranha lembrado por Lacan, ${ }^{5}$ a partir de uma referência de Spinoza, permite as apreensões possíveis do traço, da letra: um imaginário, a evocar para o sujeito, significantes constituintes de sua ficção; um simbólico, no que constitui estrutura da linguagem articulada n'alíngua materna; e, por fim, um real, algo de irredutível que insiste no traço. Assinalo aqui não se tratar do real da letra, enquanto suporte material do significante, ao que destaco, mas ao que chamaria, efeito do real: traço, incisão, marca, cicatriz.

Lacan afirmou que o real era o mistério do corpo falante, o mistério do próprio inconsciente ${ }^{6}$ Haddad,tomando um fragmento da análise de si mesmo, empreendida por Freud, encontra aí, algo que remete a esta afirmação. ${ }^{7}$ Refiro-me ao sonho de Irma, sonho que Freud designou como o sonho inaugural, abertura da via régia para o inconsciente, utilizado por Haddad para demonstrar suas hipóteses sobre as origens talmúdicas da psicanálise. No entanto, o meu interesse em apresentar a releitura do sonho freudiano diz respeito à articulação entre letra e real. Nesse sonho temos a alucinação pelo sujeito da fórmula trimetilamina sobre a qual Haddad comenta: "A alucinação no interior de um sonho não é um fenômeno banal (...) é a marca de irrupção do real, há longo tempo banido da simbolização".

Deixando de lado o que há de impreciso nesse "há longo tempo banido da simbolização", o que talvez implicasse uma cronologia e uma possibilidade de exaustão do real pelo simbólico - o que se sabe não poder ocorrer - ele elabora comentários em torno desse sonho que aludem a uma letra enquanto efeito do real. O desenho da fórmula arbórea da trimetilamina assemelha-se ao traçado de uma letra do alfabeto hebraico e, em seu Seminário, Lacan ${ }^{8}$ assinala o caráter sagrado que existiria nessa fórmula, numa alusão aos significantes hebraicos alucinados por Baltazar em seu banquete. O próprio Freud insiste em chamar atenção, para os "grossos caracteres" da fórmula, típicos da letra hebraica impressa. Ocorreria de $\mathrm{N}$ a Shin, uma transliteração, que suportaria a tradução: um deslizamento no qual o significante nome, no que implica de nome - próprio, nomeação ou palavra, insiste. Nome que Haddad vai assinalar como um dos nomes do pai, um dos nomes divinos utilizados, no judaísmo, em substituição ao nome de Deus que não deveria ser pronunciado. Shin é a primeira letra; Shadai, um destes nomes. ${ }^{9}$ Então, se o sonho inaugural para Freud, é porque trimetilamina encontra-se, homofonicamente, a morte, mét, e o sexo ha-min, além da verdade, emet, e da certeza, amim. E o tri, enquanto alusão aos três registros poderia apontar, hoje, este “(...) selo da verdade, que religa a descoberta freudiana à ordem simbólica, e seu ancoradouro de certeza do real. ${ }^{10}$

Shem, nome. Letra, marca do real no sonho de Freud. Em diversas mitologias é possível encontrar referências a palavras que não devem ser pronunciadas ou, quando o são, apenas em algumas ocasiões. Fórmulas mágicas, códigos secretos, a palavra maldita, a blasfêmia, a praga... É conhecido o efeito que a experiência da ilusão de compreender e acreditar-se compreendido, o temor de ouvir ou falar determinado nome, os atropelos cotidianos proporcionados ao sujeito por sua submissão à estrutura linguareira que o captura ao inscrevê-lo no campo do Outro. Sem a presença do nome do pai é possível que um sujeito seja excluído do uso e do usufruto do tesouro dos significantes: seus pensamentos, palavras e atos serão tomados como estranhos, trágica demonstração de que a mensagem vem sempre do Outro.

Entre as possibilidades referidas, escolhi trabalhar o nome, Shem, no que ele poderia ser articulado ao escutado na clínica: "eu não sou o senhor da palavra". Tomo aqui, nesse contexto, a palavra como algo 
de uma manifestação inequívoca do Outro, de uma divindade. De um Deus que se existisse, encontrar-se-ia no real. É na mitologia judaica que o nome, ou melhor, o nome de Deus, enquanto aquele que poderia aproximar-se à idéia do Outro, do inconsciente, encontra uma singular expressão: o tetragrama.

O tetragrama é o significante do quatro letras revelado por Deus como o seu verdadeiro nome. Ele não deveria ser pronunciado nem mesmo nas orações, e, pelo desuso, hoje já não se sabe a pronúncia correta desse nome. Os demais nomes de deus - Shadai, Eloim, Adonai, Atmon - são apenas descritivos. Habitualmente, ele é referido como ha-shem (o nome) e de acordo com a cabala, ${ }^{11}$ o mundo tal como o conhecemos mantém-se às custas desse nome, adquirindo fabulosos poderes o homem que aprender a manipular suas letras. A questão desse nome, pois, talvez interesse mais ainda ao campo psicanalítico a partir desses fragmentos da Bíblia, ${ }^{12}$ se for possível ao leitor não se limitar a um enfrentamento imaginário com a idéia de Deus: "Meu pai Davi teve a intenção de construir uma casa para o nome de Iaweh", diz Salomão. Noutro trecho, quando Moisés pergunta a Deus qual o seu nome, obtém a seguinte resposta: "Eu sou aquele que é (...) assim dirá aos filhos de Israel: Eu sou enviou-me até vós". O tempo será construído, portanto, não supondo a localização da divindade, mas para presentificá-la com seu nome (Ha-Shem): Eu sou, Iaweh. Temos, então, um nome, mas temos, também, um mais além do simbólico, algo do irredutível, de uma ilegibilidade não apenas pela interdição, mas pela impossibilidade.

O inominável, o inefável, fazendo marca pela letra e inscrevendo-se na carne. Na mitologia, é possível encontrar uma ilustração desse efeito por meio da lenda do golem, tema recorrente na literatura. $\mathrm{O}$ golem (o informe, o incriado) era um boneco de argila em tamanho natural de um homem, criado por um baal shem (literalmente, um senhor do nome: alguém que detinha o controle sobre o nome ou os nomes de Deus e realizava feitos prodigiosos com esse poder). Após moldar o boneco, o baal shem podia marcar no corpo o tetragrama ${ }^{13}$ ou colocá-lo num papel na boca do golem,,$^{14}$ juntamente com outras fórmulas cabalísticas. ${ }^{15}$ Em duas versões da lenda que prenuncia o andróide da ficção científica, após esse contágio do corpo com a letra, o boneco ganhava vida. O golem era fabricado por inspiração divina por um baal shem, tradicionalmente, em momentos nos quais a comunidade judaica sofria alguma ameaça vital. Entretanto, o golem possuía uma duração limitada, sendo sua existência permitida apenas pelo tempo necessário para eliminar o perigo para o qual ele fora exigido. Nesse momento, o baal shem apagava o tetragrama e o autômato voltava ao pó. Além disso, em hipótese alguma, seu criador poderia utilizá-lo em seu próprio beneficio e o controle de seus movimentos davase pelo manejo das letras em seu corpo. Quando momentaneamente, sua presença não era aconselhável, o baal shem apagava um pedaço da letra do tetragrama e o golem adormecia e, quando o necessitava acordado, o nome era então completado. Numa das versões, ${ }^{16}$ a mulher de um baal shem o seduz para que seja ordenado ao golem a procura de um tesouro escondido. Relutando, ele cede e utiliza o boneco em seu interesse. A partir daí, o boneco animado recusa-se a obedecê-lo e não inclina mais a cabeça para o apagamento da letra - embora ignore o que o marca e o que se tenta apagar nesta manobra - e causa sérios dissabores ao seu mestre: o sujeito começa a aparecer. Previsivelmente, desejante.

Eis a dobradiça, a articulação proposta. O tetragrama certamente evoca uma dimensão imaginária, o Deus - pai da tradição judaico-cristã na sua atualidade para cada sujeito. Existe a dimensão simbólica que remete ao Nome do Pai, à aliança estabelecida quando da apreensão do sujeito pela linguagem e da primeira simbolização: na religião judaica só após a circuncisão realizada no oitavo dia após o nascimento, os pais podem pronunciar o nome do filho, que só então se torna totalmente humano e vinculado a Deus. ${ }^{17}$ Por fim, no que interessa mais apropriadamente a este trabalho, há algo de irredutível desse nome. Abandono, agora, a mitologia no que concerne à proibição de pronunciar esse nome e aponto para a própria impossibilidade de sua leitura, audição, escritura, visão e sonorização, de um nome próprio qualquer, exauri-lo no registro do simbólico. Mas além do real das letras, desse 
suporte material do significante, dos caracteres garatujados, há um a presença real que sidera o sujeito, elemento essencial na estrutura fantasmática engendrada pela suposta demanda do Outro pela identificação resto de si que se desprende nessa nomeação, algo cai, é perdido. O nome próprio do sujeito aponta para o desejo presente na nomeação e, a estranheza que pode emergir após uma repetição inabitual - na análise, por exemplo, do seu próprio nome vem daí: uma resistência à simbolização, a letra traz em si algo não conhecido, não conhecível. Não apenas porque o simbólico não consiga exaurir o real, isso já foi dito, mas porque não algo do real irrompe no próprio simbólico: se os três registros imbricam algo do real persiste no simbólico.

E afinal, o que tem tudo isso a ver com o analista? Certamente ele não é um baal shem, embora o que ele fale ao analisante possa, sob o efeito da transferência até marcar o corpo do sujeito. $\mathrm{O}$ analista estaria aproximado à posição da mulher do baal shem no ato no qual ela faz aparecer o sujeito desejante: o baal shem cedo ao seu apelo e logo o boneco de barro percebe-se também desejante e não mais um autômato, puro objeto submetido a um apagamento. Ainda assim, ou melhor mas por isto mesmo, o nome marcado, imperceptível, desconhecido e não pronunciado continua a atá-lo ao desejo do Outro.

O analista jamais poderia apagar o nome. Ao contrário, ao dirigir a análise para um desvelamento da estrutura fantasmática que constrói o sujeito, a partir do desejo do analista que nele opera, deverá permitir que o analisante contorne algo do real que constitui seu nome próprio, seu tetragrama particular. Este nome acusa a presença do desejo do Outro e pela nomeação auferida, situar o Outro como desejante, ao marcar sua hiância e revelar o desejo do analisante enquanto desejo do Outro, o analista amortiza a dívida: ele será ainda e sempre uma dívida a pagar, mas numa recriação sintomática. Já não será a mesma, então, bordejar o real do nome próprio sustenta-lo até a ínfima parte de sua ultima letra, certamente é uma das tantas operações, um número x para cada um,. A serem realizadas pelo analisante no percurso por meio do fantasma fundamental.

Lacan, em "O avesso da psicanálise", afirma que "somos seres nascido do mais - de - gozar, resultado do emprego da linguagem. Quando digo emprego da linguagem, não quero dizer que empreguemos. Nós é que somos seus empregados. A linguagem nos emprega, e é por aí que aquilo goza. Por isso, a única chance da existência de Deus é que Ele - com E maiúsculo - goze, que ele seja o gozo" ${ }^{18}$ Quanto àquele analisante citado de início, embora nunca possa vir a ser o senhor da palavra - como nenhum de nós o é - agora pode, ainda que precariamente, evitar ser possuído e objetalizado por inteiro por esse gozo do Outro e, para seu bem e seu mal, é sujeito, em parte do tempo, pelo menos de sua palavra.

** Francisco José Bezerra Santos é Psicanalista e Membro da Escola Letra Freudiana.

* Uma versão deste artigo foi publicado, originalmente, em Pretexto - Revista de Psicanálise do Núcleo de Estudos Psicanalíticos, Ano 3, no 2, 1994, p. 50-58.

\section{Notas}

${ }^{1}$ LACAN, 1986.

2 LACAN, 1985.

${ }^{3}$ MELMAN,1986.

${ }^{4}$ LACAN, 1985.

${ }^{5}$ LACAN, 1985.

${ }^{6}$ LACAN, 1985.

${ }^{7}$ HADDAD, 1992. 


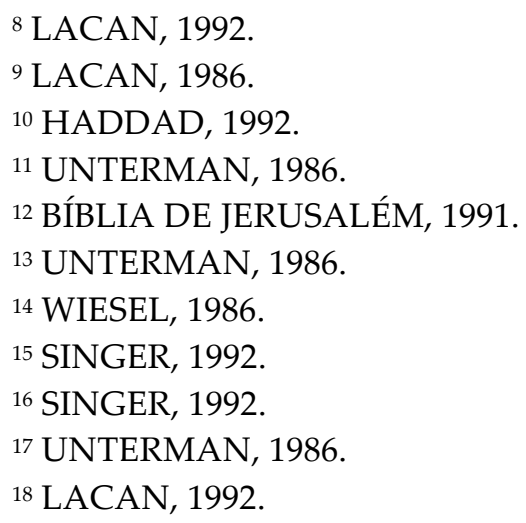

\section{Referências}

BÍBLIA DE JERUSALÉM. São Paulo: Paulinas, 1991.

HADDAD, G. O filho ilegítimo. As origens talmúdicas da psicanálise. Rio de Janeiro: Imago, 1992.

LACAN, Jacques. Mais, ainda. Seminário. Livro 20. Rio de Janeiro: Jorge Zahar, 1985.

LACAN, Jacques. O avesso da psicanálise. Seminário. Livro 17. Rio de Janeiro: Jorge Zahar, 1992.

LACAN, Jacques. O eu na teoria de Freud e na Técnica da psicanálise. Seminário. Livro 2. Rio de Janeiro: Jorge Zahar, 1992.

LACAN, Jacques. Os nomes do Pai. Seminário de 20/11/63. In: Che Vuoi. № 02. Porto Alegre: Cooperativa Cultural J. Lacan, 1986.

MELMAN, C. O sintoma e a clínica de Lacan. In: Che Vuoi. № 02. Porto Alegre: Cooperativa Cultural J. Lacan, 1986.

SINGER, I. B. O golem. São Paulo: Perspectiva, 1992.

UNTERMAN, A. Dicionário judaico de lendas e tradições. Rio de Janeiro: Jorge Zahar, 1986.

WIESEL, I. B. O golem: a história de uma lenda. Rio de Janeiro: Imago, 1986. 